\title{
A Study on the Reliability and Validity of PETS Oral Test
}

\author{
Zhang Ning, Wang Chunjuan, Wang Caixia
}

Shandong Jiaotong University, Weihai, Shandong

Keywords: PETS, reliability, validity

\begin{abstract}
This paper analyzes the reliability and validity of oral test of PETS. It also investigates measures that should be taken to improve the reliability and validity through perspectives such as oral test teachers' ability, the examination environment, oral test questions and the optimization of grading standards and scoring methods.
\end{abstract}

\section{Introduction}

Public English Test System (PETS) is designed and developed by the examination center of Ministry of Education for the whole society. It is an open and non-academic English level examination. PETS score has been an important basis for employing employees in many companies, especially in some foreign enterprises. PETS consists of five levels and one subordinate level, each of which is divided into written and oral examinations. The purpose of the oral examination is to test the oral expression ability of the examinee. Therefore, oral test is a subjective test. Therefore, the reliability and validity of the oral test can be the focus of attention and research. There are not only some basic contents but also some high level contents in oral test of PETS-3 since it is at the middle of the five levels, which is representative in the whole PETS oral test system. As a result, the oral test of PETS-3 is chosen as the object of the present study.

\section{PETS examination form and scoring standard}

This section mainly focuses on three parts, which are the examination form, question types and contents and scoring standard.

\subsection{Examination form of PETS oral test}

PETS oral test takes the form of face to face direct oral test. Two oral examiners conduct an oral examination on two examinees at the same time. During the test, interlocutor conducts oral examination and is responsible for talking to examinees and giving overall impression scores. Assessor is merely responsible for scoring and does not participate in the conversation. The oral test time for PETS-3 is 10 minutes and the total score is 5, with 3 as the passing grade.

\subsection{Question types and contents of PETS oral test}

Table 1: Question types and contents of PETS-3 oral test

\begin{tabular}{|c|c|c|c|c|}
\hline Parts & Contents & Aim & Form & Time \\
\hline A & $\begin{array}{l}\text { Two examinees provide } \\
\text { personal information and } \\
\text { answer questions about study, } \\
\text { life, work, family, social } \\
\text { culture, etc. }\end{array}$ & $\begin{array}{l}\text { Make the examiners } \\
\text { learn something about } \\
\text { the examinees and } \\
\text { ease the tension of the } \\
\text { examinees. }\end{array}$ & $\begin{array}{l}\text { Interlocutor talks } \\
\text { to two examinees } \\
\text { separately. }\end{array}$ & $3 \mathrm{~min}$ \\
\hline B & $\begin{array}{l}\text { Examinees have a discussion } \\
\text { about pictures or words on the } \\
\text { exam paper. }\end{array}$ & $\begin{array}{l}\text { Test examinees' ability } \\
\text { to cooperate and } \\
\text { discuss related issues. }\end{array}$ & $\begin{array}{l}\text { Two examinees } \\
\text { talk to each } \\
\text { other. }\end{array}$ & $3 \mathrm{~min}$ \\
\hline $\mathrm{C}$ & $\begin{array}{l}\text { One examinee gives a brief } \\
\text { description of the picture or } \\
\text { words on the exam paper. After } \\
\text { that the other examinee } \\
\text { expresses his own opinion on } \\
\text { the same topic. }\end{array}$ & $\begin{array}{l}\text { Test the examinees' } \\
\text { ability to express on the } \\
\text { same subject } \\
\text { continuously. }\end{array}$ & $\begin{array}{l}\text { Two examinees } \\
\text { finish the task } \\
\text { separately. }\end{array}$ & $4 \mathrm{~min}$ \\
\hline
\end{tabular}


PETS-3 oral test includes three parts named A, B and C, which are shown in Table 1 in detail.

\subsection{Scoring standard of PETS oral test}

The scoring of PETS-3, like other levels, is composed of two parts. They are overall scores by the interlocutor and itemized scores by the assessor, which are shown in Table 2 in detail.

Table 2: Scoring standard of PETS-3 oral test

\begin{tabular}{|c|c|c|c|c|}
\hline \multicolumn{2}{|c|}{ Grading category } & Grader & $\begin{array}{l}\text { Score } \\
\text { range }\end{array}$ & $\begin{array}{c}\text { Assumed } \\
\text { score }\end{array}$ \\
\hline $\begin{array}{l}\text { Overall } \\
\text { scores }\end{array}$ & Overall performance & Interlocutor & $0-5$ & A \\
\hline \multirow{4}{*}{$\begin{array}{l}\text { Itemized } \\
\text { scores }\end{array}$} & Grammar and vocabulary & \multirow{4}{*}{ Assessor } & $0-5$ & $\mathrm{~B}_{1}$ \\
\hline & Discourse application & & $0-5$ & $\mathrm{~B}_{2}$ \\
\hline & Pronunciation and intonation & & $0-5$ & $\mathrm{~B}_{3}$ \\
\hline & Interactive communication & & $0-5$ & $\mathrm{~B}_{4}$ \\
\hline
\end{tabular}

According to the scoring standard, the actual score of the examinee " $\mathrm{S}$ " is calculated on the basis of the following formula:

$$
S=\frac{2 A+B_{1}+B_{2}+B_{3}+B_{4}}{6}
$$

The examinee passes the oral test if $S \geq 3$. Two examiners cannot discuss over the grades they offer. Instead, they are supposed to judge by their own scoring standard respectively. The proportion of their grade is $\mathrm{A}: \mathrm{B}=1: 2$.

\section{Influential factors of the reliability and validity of PETS-3 oral test}

This part mainly focuses on what the reliability and the validity are as well as the factors that can influence the reliability and validity of PETS-3 oral test.

\subsection{PETS-3 oral test's reliability and its influential factors}

Test reliability refers to whether the results of the language tests are stable and reliable, reflecting the consistency of the test results. As a face-to-face direct oral test, PETS-3 oral test reflects the real life situation and has a high surface credibility. The examinees' oral English proficiency remains basically unchanged in a short period of time, so the reliability of the oral examination depends on the stability of the score given by the examiners to a large extent. Two examiners assess together and the examinee's actual score is gotten comprehensively by way of the above formula. It is more reasonable than only one examiner and can enhance the fairness of the score to a large extent. However, different competency and strong subjectivity of the examiners may influence the reliability of the oral test.

What's more, it will also affect the reliability of the oral test if there is difference in the understanding of the scoring criteria between the two examiners.

\subsection{PETS-3 oral test's validity and its influential factors}

Test validity refers to the extent to which the test examines the content that the examination wishes to examine. In other words, test validity refers to whether the exam has achieved its intended purpose and whether the results reflect the actual language level of the examinee. PETS-3 oral test consists of three parts and the wide coverage of the test content avoids the situation that examinees can not fully show their oral ability because of the single type of question to a certain extent, which reflects its high test validity. Nevertheless, this special type of questions and scoring standard also affect its validity, which can be shown in the following three aspects.

\subsubsection{The influence of the examinees' nervousness}

The first part of PETS-3 oral test aims to make the examiners learn about the examinees and mitigate the nervousness of the examinees. However, the writer finds in the process of oral test that 
some examinees are quite difficult to adapt to the face to face communication between examiners and examinees. The examinees show tremendous nervousness from the beginning. Their nervousness cannot be mitigated through conversations and they are unable to show their real English level, thus affecting the validity of the oral test.

\subsubsection{The influence of the examinations' questions}

The second and third parts of PETS-3 oral test make up for the information gap in the oral instructions by the examiners through pictures and words to help examinees understand the oral test questions. However, some examinees are lacking in interest in the topic, have nothing to talk about the topic, or are obsorbed in personal statements without interaction, resulting in the lack of adequate corpus to allow the examiners to assess the real language level of the examinees and influencing the oral test's validity.

\subsubsection{The influence of pronunciation}

The itemized scoring standard of PETS-3 by the assessor is composed of grammar and vocabulary, discourse application, pronunciation and intonation and interactive communication. The three parts of the oral test offers reasonable assessment to grammar and vocabulary, discourse application and interactive communication. However, the assessment of pronunciation is not so appropriate. Examinee is prone to make mistakes in the pronunciation of some phonemes in the English phonetic alphabet, such as $[\theta] 、[ð] 、[f],[3],[\mathrm{t}],\left[\mathrm{d}_{3}\right]$, and so on. The pronunciation performance of the examinee is not easily fully tested if the oral test tests pronunciation simply through dialogue and statements. As a consequence, the real pronunciation level of the examinees can not be measured appropriately if some examinees are lacking in interest in the topic or have nothing to talk about the topic, thus influencing the validity of the oral test.

\section{Suggestions to improve the reliability and validity of PETS oral test}

In order to improve the reliability and validity of PETS oral test some suggestions are put forward.

\subsection{Emphasizing the training of examiners}

Training of the examiners is essential since the reliability of PETS oral test can be influenced by different competency, strong subjectivity and difference in the understanding of the scoring criteria between the two examiners. The provincial examination institute will organize the training of the examiners before each test. A comprehensive training for the examiners should be conducted. The training ranges from knowledge updating, examination process, scoring criteria to the handling of emergencies, and so on. The training should be combined with video record and other methods, so that the examination process should be kept in mind by the examiners. In addition, there is one point that must be emphasized during the training. It is that the guiding language during the test is carefully designed, and the interlocutor is not allowed to play it at will, which is an important factor to ensure the reliability and validity of the oral test.

\subsection{Building a harmonious and friendly examination environment}

Friendly environment helps the examinees to ease their tension and show their real oral English competency. Harmonious envrionent can be presented in some details.

\subsubsection{Correct guidance of the waiting room teachers}

Waiting room teachers exert certain influence on mitigating the examinees' tension. Waiting room teachers create an orderly waiting order and guide the examinees to match their own group before oral examination, which can help examinees to ease their tension and become familiar with their partners. 


\subsubsection{Friendly layout of the examination room}

The details in the examination room will also affect the mood of the examinees. The tables and chairs should not be too far away from the door of the examination room in case that the examinees should be nervous about passing through the room under the nose of the examiners. The layout of the examination room should not let the examinees face the light or the light shine from the back of the examiners. The examiners and examinees should avoid sitting face to face as to the arrangement of seats. Instead, the two sides should sit at right angle for fear that it should make the examinees be nervous.

\subsubsection{Moderate adjustment of atmosphere by the examiners}

The goal of the first part of the oral test is to help relieve the examinees' tension. However, most examinees are quite nervous when they enter the examination room and they regard the interlocutor's questions as an aggravation. Examiners should adjust the atmosphere and create a relaxed and friendly environment. During the oral test, the interlocutor is supposed to keep smile while communicating with the examinees. The proper arrangement of seats and the appropriate adjustment of atmosphere can help to relieve the examinees' tension and put forward their real oral English competency, thus enhancing the validity of the PETS oral test.

\subsection{Giving full play to the guiding role of the examiners}

In addition to showing the questions clearly to the examinees, the interlocutor should also give proper guidance to the examinees. For example in part B, two exmainees are required to talk to each other about one topic. The writer finds in the process that some examinees consider part B as a statement of personal opinion, or take the interlocutor as the object of communication. When it occurs, the interlocutor should conduct the examinees properly and interrupt politely with words such as "Excuse me, please talk with each other" to encourage the examinees to talk to each other. When the examinees' output of spoken English is not so sufficient for the examiners to assess, the interlocutor may make appropriate but not too many hints to encourage examinees to continue to communicate so as to avoid the situation that the output of the exmainees is too low for the examiners to assess.

\subsection{Suggestions on oral test questions}

Oral test questions can be optimized by way of several aspects.

\subsubsection{Oral test questions should be as popular as possible}

Questions for PETS oral test should be close to the study and daily life of the examinees. At the same time, different interests as a result of gender difference should also be taken into consideration. Girls tend to be more interested in fashion, while boys may be more interested in politics, military, current events, etc.

\subsubsection{Enrich oral test question types}

The three parts of the oral test aim to test examinees' active language output and offer reasonable assessment to grammar and vocabulary, discourse application and interactive communication. However, the assessment of pronunciation is not so appropriate. As has been discussed above, some examinees are lacking in interest in the topic or have nothing to talk about the topic, resulting in the lack of adequate corpus to allow the examiners to assess the real language competency of the examinees and influencing the oral test's validity. Therefore, the writer suggests that oral test question types should be enriched. For example, question types about reading aloud can be added and some easily confusing phonemes should be included in these question types.

\subsection{Optimizing grading category and score range}

Grading category and score range can be optizmized according to some recommendations. 


\subsubsection{Recommendations for optimization of grading category}

The scoring of PETS-3 is composed of two parts, overall scores by the interlocutor and itemized scores by the assessor. The grading categories by the assessor are grammar and vocabulary, discourse application, pronunciation and intonation and interactive communication, which highlights the accuracy of the examinees' output and the interactivity of communication, but it does not involve the fluency of the output. In order to pursue the accuracy of the language form, some examinees often ignore the communication efficiency and speak hesitantly. Therefore, the writer suggests that "fluency" should be added to the four items. Consequently, the examinees' real oral English competency can be fully tested, thus enhancing the reliability of the oral test.

\subsubsection{Calculation of the actual score based on the above recommendations}

According to the above recommendations, "fluency" is added to the four items of the assessor, and the score range becomes 0-9. Then the new scoring standard of PETS-3 oral test is shown in Table 3.

Table 3 Optimized scoring standard of PETS-3 oral test

\begin{tabular}{|c|c|c|c|c|}
\hline \multicolumn{2}{|c|}{ Grading category } & Grader & Score range & Assumed score \\
\hline $\begin{array}{l}\text { Overall } \\
\text { scores }\end{array}$ & Overall performance & Interlocutor & $0-9$ & A \\
\hline \multirow{5}{*}{$\begin{array}{l}\text { Itemized } \\
\text { scores }\end{array}$} & Grammar and vocabulary & \multirow{5}{*}{ Assessor } & $0-9$ & $\mathrm{~B}_{1}$ \\
\hline & Discourse application & & $0-9$ & $\mathrm{~B}_{2}$ \\
\hline & Pronunciation and intonation & & $0-9$ & $\mathrm{~B}_{3}$ \\
\hline & Interactive communication & & $0-9$ & $\mathrm{~B}_{4}$ \\
\hline & Fluency & & $0-9$ & $\mathrm{~B}_{5}$ \\
\hline
\end{tabular}

The proportion of their grade is $A: B=1: 2$. The actual score of the examinee " $\mathrm{S}$ ' ” is calculated on the basis of the following formula:

$$
S^{\prime}=\frac{2.5 A+B_{1}+B_{2}+B_{3}+B_{4}+B_{5}}{7}
$$

The value of $S^{\prime}$ should be rounded without a decimal. The examinee passes the oral test if $S^{\prime}$ $\geq 5$.

\section{References}

[1] J. B. Heaton. Writing English Language Tests. Beijing. Foreign Language Teaching and Research Press. 2007.

[2] Li Lili. Reliability and Validity Analysis of Oral English Test. Journal of Shijiazhuang Vocational Technology Institute. 2008, 20 (1).

[3] Li Xiaoju. Science and Art of Language Testing. Changsha. Hunan Education Press. 2001.

[4] William Littlewood. Foreign and Second Language Learning. Beijing. Foreign Language Teaching and Research Press. 2000. 